\title{
Innate immunity turned inside-out: antimicrobial defense by phagocyte extracellular traps
}

\author{
Maren von Köckritz-Blickwede • Victor Nizet
}

Received: 11 March 2009/Revised: 15 April 2009 /Accepted: 23 April 2009/Published online: 16 May 2009

(C) The Author(s) 2009. This article is published with open access at Springerlink.com

\begin{abstract}
The formation of extracellular traps (ETs) by phagocytic cells has been recognized as a novel and important mechanism of the host innate immune response against infections. ETs are formed by different host immune cells such as neutrophils, mast cells, and eosinophils after stimulation with mitogens, cytokines, or pathogens themselves, in a process dependent upon induction of a reactiveoxygen-species-mediated signaling cascade. ETs consist of nuclear or mitochondrial DNA as a backbone with embedded antimicrobial peptides, histones, and cellspecific proteases and thereby provide a matrix to entrap and kill microbes and to induce the contact system. This review summarizes the latest research on ETs and their role in innate immunity and host innate defense. Attention is also given to mechanisms by which certain leading bacterial pathogens have evolved to avoid entrapment and killing in these specialized structures.
\end{abstract}

M. von Köckritz-Blickwede $(\bowtie) \cdot$ V. Nizet

Department of Pediatrics, University of California,

9500 Gilman Drive, La Jolla, Mail Code 0687, San Diego, CA

92093-0687, USA

e-mail: maren@ucsd.edu

V. Nizet $(\bowtie)$

Skaggs School of Pharmacy and Pharmaceutical Sciences,

University of California,

Mail Code 0687, La Jolla,

San Diego, CA 92093-0687, USA

e-mail:vnizet@ucsd.edu

V. Nizet

Rady Children's Hospital,

San Diego, CA, USA
Keywords Neutrophil · Mast cell · Eosinophil ·

Extracellular trap · Innate immunity - Bacterial infection ·

Virulence factors - Antimicrobial peptides · DNA · Histones ·

Mitochondria

\section{Introduction}

The frontline function of phagocytes such as neutrophils and macrophages in our innate immune defense has been classically understood to reflect a variety of potent intracellular microbicidal mechanisms. Upon contact with the invading pathogen, phagocytes engulf the microbes into their phagocytic vacuoles (phagosomes). Efficient uptake is facilitated through prior opsonization of the microbe with circulating complement or, in the nonnaïve host, specific antibodies recognizing epitopes on the pathogen surface. Phagosomes subsequently fuse with intracellular granules to form the phagolysosome, within which microbial killing is achieved by a combination of nonoxidative and oxidative mechanisms $[1,2]$. Potent nonoxidative killing mechanisms include antimicrobial peptides (AMPs) such as cathelicidins and defensins and the activities of cathepsins and other degradative proteases; the oxygen-dependent "respiratory burst" involves the nonmitochondrial generation of antimicrobial reactive oxygen species (ROS) through the membrane-bound NADPH oxidase enzyme complex.

However, beginning with a landmark study in 2004 [3], the fundamental conception of how, and where, neutrophils kill pathogenic microbes has been altered in a most fascinating and provocative way. The discovery of DNAbased antimicrobial extracellular traps (ETs) elaborated by neutrophils (NETs) has important implications for our understanding of the innate immune system and the pathophysiology of infectious and inflammatory diseases. 
And with recent data indicating that this phenomenon is not restricted to neutrophils but shared by other specialized leukocytes, one has the sense that we are at the inception of a major field of investigation whose ramifications may be quite far-reaching. Here, we summarize current knowledge of ETs and their functions in innate host defense.

\section{Neutrophil extracellular traps}

The phenomenon of NETs, as well as their basic structure and function, was first discovered by Brinkmann et al. using electron microscopy [3]. NETs were observed as a highly decondensed chromatin structure that is formed and released by activated neutrophils. Since treatment with DNase led to the disintegration of NETs, DNA was ascertained to represent the major structural component a backbone upon which histones, proteases (e.g. elastase), and AMPs reside. The fibrous DNA stretches within NETs had a diameter of 15-17 nm, punctuated with globular protein domains ranging from $\sim 25 \mathrm{~nm}$ up to large aggregates of $\sim 50 \mathrm{~nm}$. It was surmised that the cationic proteins embedded within the NETs such as histones or cathelicidin AMPs confer an ability to kill entrapped microbes. This concept was validated when efficient killing of bacteria such as Staphylococcus aureus and Listeria monocytogenes by neutrophils occurred even when phagocytosis was blocked pharmacologically (cytochalasin D, an actin microfilament inhibitor). Moreover, this extracellular antimicrobial activity was eliminated by DNase treatment and dissolution of the NET architecture [3]. Our own threedimensional confocal micrograph of $S$. aureus entrapped within human NETs is presented in Fig. 1.
A variety of different proinflammatory stimuli have been shown to activate the formation of ETs (Table 1), including hydrogen peroxide $\left(\mathrm{H}_{2} \mathrm{O}_{2}\right)$, bacterial lipopolysaccharide (LPS), the mitogen phorbol myristate acetate (PMA), and the CXC family chemokine interleukin 8 (IL-8) [3, 4]. The chemotactic complement-derived peptide complement factor 5a (C5a) can also stimulate NET formation but only after mature neutrophils are primed with interferons or granulocyte macrophage colony-stimulating factor (GMCSF) [5]; no such priming step is required for NET induction with LPS, PMA, or IL-8 [3]. Platelets activated in a TLR4-dependent fashion can also induce NETs, promoting the trapping of bacteria within blood vessels [6]. And as would befit a critical innate immune process, direct exposure to a variety of different microbial pathogens is sufficient to trigger NET formation, including $S$. aureus [4], Streptococcus pyogenes [7], Mycobacterium tuberculosis [8], Escherichia coli [9], hyphae or yeast forms of Candida albicans [10], and the protozoan parasite Leishmania amazonensis [11]. Studies with C. albicans suggest that prior opsonization of the pathogen can increase the NET response [10]. Recently, an individual bacterial protein, the surface-anchored and soluble M1 protein of $S$. pyogenes, was found sufficient to induce NET formation $[12,13]$, adding to its described proinflammatory properties [14]. Surface lipophosphoglycan purified from L. amazonensis is also capable of inducing nets in a dose-dependent fashion [11].

Knowledge is beginning to emerge regarding the cellular processes that precede the formation of NETs by activated neutrophils (summarized in Fig. 2). Evidence implicates the production of ROS such as superoxide $\left(\mathrm{O}_{2}{ }^{-}\right)$or $\mathrm{H}_{2} \mathrm{O}_{2}$ as an essential signal leading to the induction of unique cell death
Fig. 1 Bacterial entrapment in NETs: three-dimensional confocal micrograph of FITC-labeled S. aureus (strain Cowan) entrapped by human neutrophil extracellular traps, as visualized by the blue DNA dye DAPI

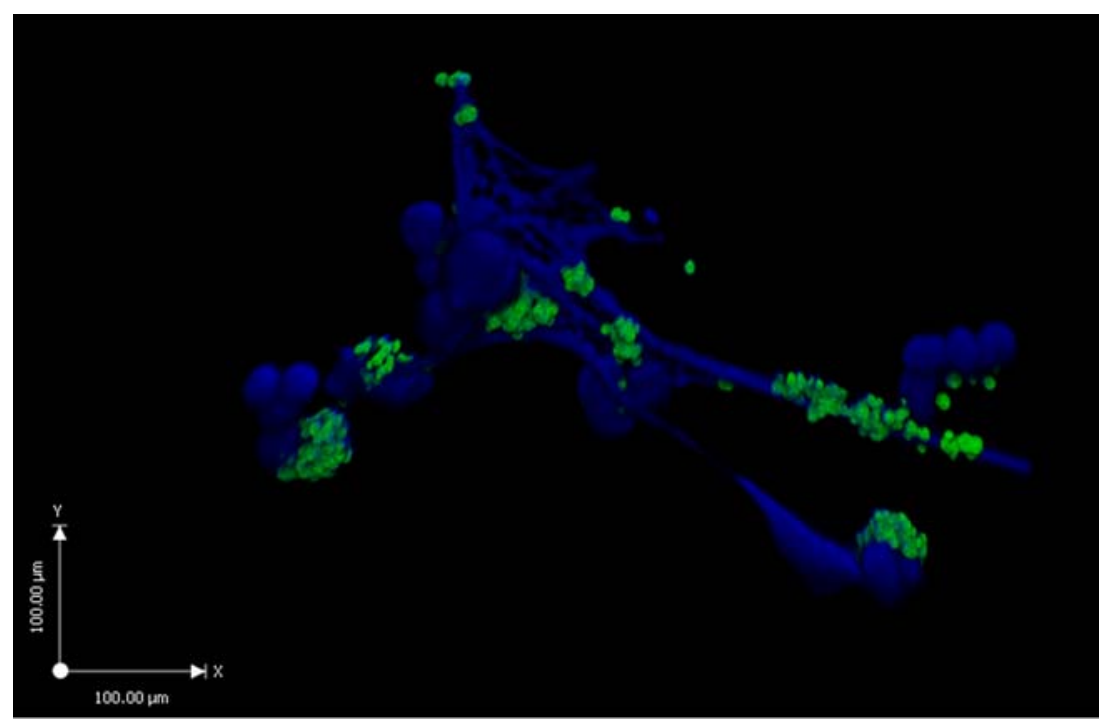


Table 1 Factors or microbes inducing formation of extracellular traps

\begin{tabular}{|c|c|c|}
\hline Factor or Microbe & Cellular origin of extracellular trap & References \\
\hline Interleukin 8 (IL-8) & Neutrophils & [3] \\
\hline Lipopolysaccharide (LPS) & Neutrophils & [3] \\
\hline Phorbol myristate acetate (PMA) & Neutrophils, mast cells & {$[3,21]$} \\
\hline Hydrogen peroxide & Neutrophils, mast cells & {$[4,21]$} \\
\hline Platelet TLR-4 & Neutrophils & {$[6]$} \\
\hline Interferon (IFN) $\gamma+\mathrm{C} 5 \mathrm{a}$ & Neutrophils, eosinophils & {$[5,32]$} \\
\hline Interferon (IFN) $\gamma+$ LPS & Eosinophils & {$[32]$} \\
\hline Interferon (IFN) $\gamma+$ eotaxin & Eosinophils & {$[32]$} \\
\hline IL-5 + LPS/C5a/eotaxin & Eosinophils & {$[32]$} \\
\hline Interferon (IFN) $\alpha+\mathrm{C} 5 \mathrm{a}$ & Neutrophils & {$[5]$} \\
\hline GM-CSF + C5a & Neutrophils & {$[5]$} \\
\hline Staphylococcus aureus & Neutrophils, mast cells & {$[4,21]$} \\
\hline Streptococcus pyogenes & Neutrophils, mast cells & {$[7,21]$} \\
\hline \multicolumn{3}{|l|}{ Streptococcus pyogenes } \\
\hline M1 protein-fibrinogen complex & Neutrophils, mast cells & {$[12,13]$} \\
\hline Pseudomonas aeruginosa & Mast cells & {$[21]$} \\
\hline Mycobacterium tuberculosis & Neutrophils & [8] \\
\hline Mycobacterium canettii & Neutrophils & {$[8]$} \\
\hline Candida albicans (hyphae or yeast) & Neutrophils & {$[10]$} \\
\hline Escherichia coli & Neutrophils & [9] \\
\hline Leishmania amazonensis & Neutrophils & [11] \\
\hline Leishmania amazonensis, surface lipophosphoglycan & Neutrophils & [11] \\
\hline
\end{tabular}

program and the elaboration of NETs [4]. Interference with ROS generation using diphenylene iodonium (DPI), an inhibitor of NADPH oxidase enzymes, blocks the formation of NETs. This process is morphologically distinct from other classical cell death processes including apoptosis and necrosis and hence was dubbed "NETosis" [15]. One key biochemical marker of NET formation appears to be the deimination of arginine residues in histones to citrullines, a posttranslational modification catalyzed by peptidyl arginine deaminase that aids in chromatin decondensation. Hypercitrullinated histones were detected in NETs released by neutrophils activated by LPS and $\mathrm{H}_{2} \mathrm{O}_{2}$ but not in neutrophils treated with staurosporine or camptothecin to induce apoptosis $[16,17]$.

In NETosis, global chromatin decondensation and disintegration of the nuclear membrane occurs concomitant with cytoplasmic granule dissolution, allowing the NET components to mix in the cytoplasm prior to their extracellular release $[4,15]$. The negatively charged DNA backbone of NETs also provides a framework for activation of the contact system [13], which is comprised of the serum-derived serine proteases factor XI, factor XII, and plasma kallikrein together with the nonenzymatic highmolecular-weight cofactor, kininogen [18]. Activation of the contact system results in generation of the potent proinflammatory mediator bradykinin, as well as breakdown peptide fragment of HK with potent antimicrobial properties [19]. The humoral pattern recognition receptor pentraxin 3 is also present in neutrophil-specific granules and localizes to NETs where it may play a role in the control of fungal pathogens such as Aspergillus fumigatus [20].

\section{Mast cell extracellular traps}

ET formation was first thought to be restricted to neutrophils, as stimulation of peripheral blood mononuclear cells with PMA or $\mathrm{H}_{2} \mathrm{O}_{2}$ did not induce release of similar DNA-based extracellular structures [4]. However, recent investigations have revealed that another tissue granulocyte important to innate host defense, the mast cell (MC), is also able to elaborate its nuclear DNA to produce antimicrobial ETs [21].

MCs are prevalent at sites interfacing with the environment such as the respiratory tract and skin. Largely studied in the context of allergic diseases [22], the role of MCs in host defense against bacterial pathogens has attracted increasing attention [23]. MCs prestore tumor necrosis factor $\alpha$ in their secretory basophilic granules, which can be released immediately upon activation by pathogens to promote early neutrophil recruitment and bacterial clearance [24]. MCs 


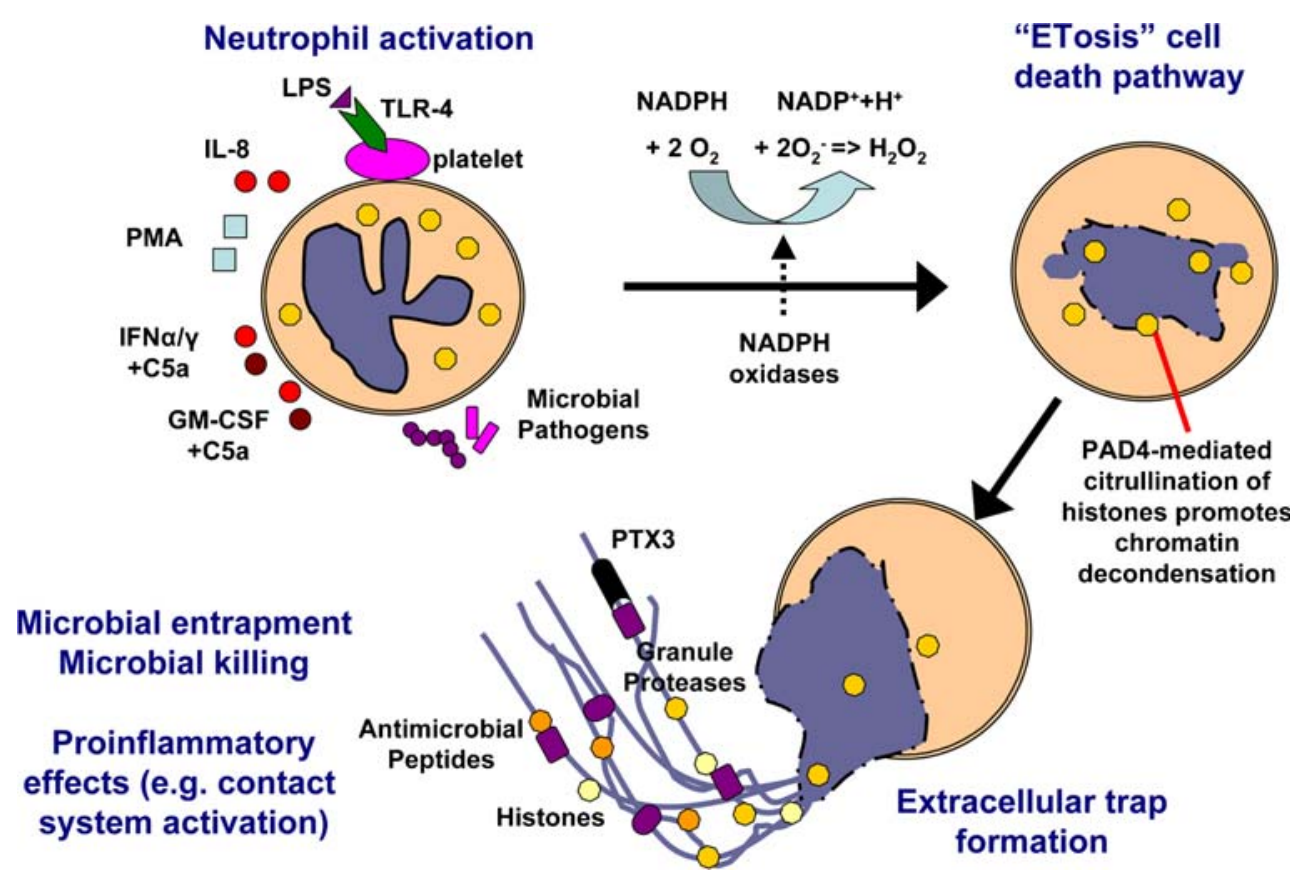

Fig. 2 Model for formation of neutrophil extracellular traps. Neutrophils are activated by contact with microbial pathogens different stimuli such as LPS, IL-8, PMA, IFN- $\alpha / \gamma+$ C5a or GM$\mathrm{CSF}+\mathrm{C} 5 \mathrm{a}$. Stimulation of neutrophils results in the activation of $\mathrm{NADPH}$ oxidases and the formation of reactive oxygen species (ROS). ROS signaling is required for the novel cell death pathway of ETosis, which is characterized by the disruption of the nuclear membrane, chromatin decondensation, and the mixing of nuclear contents with cytoplasmic and granular proteins. As a final step, nuclear and granular components are released by the dead cell generating the extracellular traps. Extracellular traps have the ability to entrap and/or kill different microbes, while also enhancing proinflammatory innate immune responses have also been shown to directly kill bacteria after intracellular uptake through oxidative and nonoxidative antimicrobial mechanisms, similar to traditional phagocytes such as neutrophils and macrophages [25]. Potent broad-spectrum AMPs such as cathelicidin and $\beta$-defensins are present in MC granules and are secreted upon bacterial stimulation [26, 27].

Recently, confocal fluorescent microscopy and scanning electron microscopy were used to demonstrate that both human and murine MCs exert extracellular antimicrobial activity through ROS-dependent dissolution of the nuclear membrane and elaboration of structures that strongly resembled NETs [21]. Mast cell extracellular trap (MCET) production was documented in response to various pathogens including $S$. aureus, Pseudomonas aeruginosa, and $S$. pyogenes [21] and, like NET formation, in response to the purified M1 protein of $S$. pyogenes [12]. The major components of human MCETs are DNA, histones, MCspecific granule proteins such as tryptase, and the cathelicidin AMP LL-37. Bacterial entrapment was required for antimicrobial activity since dismantling the MCETs structure strongly reduced bacterial killing [21]. However, in contrast to NETs, DNase alone was not sufficient to dismantle MCETs; additional treatment with tryptasedegrading myeloperoxidase was required for this purpose. Wartha and Henriques-Normark [28] have recently recom- mended recoining the term "NETosis" to "ETosis," consistent with the relevance of this phenomenon for additional cell types.

\section{Catapulting mitochondria and eosinophil extracellular traps}

Eosinophils, sharing many similarities with $\mathrm{MC}$, are a specialized and rather enigmatic granulocytic cell type derived from the bone marrow. Generally residing in hematopoietic and lymphatic organs such as the spleen and lymph nodes [29], eosinophils can also infiltrate stomach, small intestine, and colon, where they are seen in association with inflammatory bowel disease (IBD) and a spectrum of conditions now known as eosinophil-associated gastrointestinal disorders (EGIDs) [30, 31]. Although the reliable induction of eosinophil counts in response to parasitic nematode infections suggest they serve an immune role, the exact function(s) of eosinophils in host defense have remained unclear.

However, very recently, Yousefi et al. identified a remarkable phenomenon of catapult-like ejection of mitochondrial DNA by eosinophils with the potential to contribute to antibacterial defense [32]. Examining infectious foci from biopsies of patients with IBD or 
intestinal spirochetosis, the authors observed DNAcontaining material extruding from gastrointestinal eosinophils. The authors then showed that, when blood eosinophils were primed in vitro with IL-5 or interferon $\gamma$ (IFN- $\gamma$ ) and subsequently stimulated with LPS, C5a, or the eosinophil chemokine eotaxin, they would release mitochondrial (but not nuclear) DNA, thus forming extracellular traps containing antibacterial eosinophilic cationic protein and major basic protein [32]. Similar to NETs and MCETs, treatment with DNase resulted in the disappearance of the eosinophil-derived extracellular DNA structures and in the abolishment of extracellular bacterial killing.

Like NETs and MCETs, the eosinophil ET process is dependent on ROS production but importantly does not represent a specialized form of cell death since the eosinophil remains viable after ejection of its mitochondrial DNA (differences highlighted in Table 2). A role in defense of compromised gastrointestinal epithelium is postulated, and transgenic hypereosinophilic mice were shown to be less susceptible to septicemia following cecal ligation puncture [32]. However, the in vivo function of eosinophil-derived ETs remains to be demonstrated, and it is at least conceivable that the release of proinflammatory eosinophil contents represents part of the underlying pathophysiology of IBD and EGID, as opposed to an adaptive antibacterial defense mechanism [33].

\section{Association of ETs with specific disease conditions}

There is increasing evidence that ETs play an important role in several infectious as well as noninfectious diseases (Table 3). The literature to date has demonstrated how a variety of microbes are entrapped within and/or killed by
ET: Gram-positive bacteria ( $S$. aureus, $S$. pyogenes, $S$. pneumoniae, L. monocytogenes), Gram-negative bacteria (E. coli, Salmonella enterica, Shigella flexneri, Haemophilus influenzae, Pseudomonas luminescens), mycobacteria (M. tuberculosis), fungi (C. albicans), and parasites ( $L$. amazonensis). It remains uncertain whether viruses are entrapped by ETs. The molecular mechanisms involved in entrapment of the microbes are not known, but it is postulated that electrostatic interactions between the cationic component of NETs and the anionic surface of microorganisms play a role in this process [34]. After disruption of extracellular traps with DNase or DNase/ proteinase mixtures, the extracellular antimicrobial activity of neutrophils, eosinophils, or MCs is eliminated [4, 21, 32].

Several studies have provided in vivo demonstrations of ET formation during infection, including spontaneous human appendicitis [3], children with Plasmodium falciparum malaria [35], patients with cutaneous leishmaniasis [11], Shigella-induced experimental dysentery in rabbits [3], H. influenzae-associated otitis media in chinchillas [36], murine models of pneumococcal pneumonia [37], $S$. pyogenes necrotizing soft tissue infection [7], and polymicrobial sepsis after cecal ligation and puncture [32]. Recently, NETs were also detected in bovine mastitis induced by pathogenic E. coli, where neutrophil phagocytosis and oxidative burst have been shown to be hampered by milk fat, proteins, or hyperketonemia [9, 38].

If ETs indeed serve a critical innate immune function, then deficiencies in ET formation would be postulated to render the individual host more susceptible to infection. Some evidence is beginning to emerge along these lines. For example, human newborns are known to have qualitative defects in neutrophil function that contribute to sepsis and other infectious complications.

Table 2 Comparison of formation of extracellular traps by different cell types

\begin{tabular}{|c|c|c|c|}
\hline & Neutrophils & Mast cells & Eosinophils \\
\hline Main backbone & DNA & DNA, tryptase & DNA \\
\hline $\begin{array}{l}\text { Degradation of } \\
\text { traps }\end{array}$ & DNase & $\begin{array}{l}\text { DNase (tryptase- } \\
\text { degrading) } \\
\text { myeloperoxidase }\end{array}$ & DNase \\
\hline $\begin{array}{l}\text { Further } \\
\text { identified } \\
\text { components }\end{array}$ & $\begin{array}{l}\text { Histones, elastase, myeloperoxidase, cathepsin G, LL-37, PTX-3, } \\
\text { gelatinase, lactoferrin, bactericidal permeability increasing pro- } \\
\text { tein (BPI), peptidoglycan recognition proteins (PGRPs) }\end{array}$ & Histones, LL-37 & $\begin{array}{l}\text { Eosinophilic cationic protein } \\
(\mathrm{ECP}) \text {, major basic protein } \\
(\mathrm{MBP})\end{array}$ \\
\hline Final cell status & Dead & Dead & Alive \\
\hline $\begin{array}{l}\text { ROS } \\
\text { dependent }\end{array}$ & Yes & Yes & Yes \\
\hline Origin of DNA & Nuclear & Nuclear & Mitochondrial \\
\hline $\begin{array}{l}\text { Disruption of } \\
\text { nuclear } \\
\text { membrane }\end{array}$ & Yes & Yes & No \\
\hline Time frame & $10 \min$ to $4 \mathrm{~h}$ & $10 \mathrm{~min}$ to $4 \mathrm{~h}$ & Seconds \\
\hline
\end{tabular}


Table 3 Association of extracellular traps with diseases

\begin{tabular}{|c|c|c|}
\hline Infectious disease & Role of extracellular traps & References \\
\hline Staphylococcus aureus & Capture and kill bacteria & {$[3]$} \\
\hline Streptococcus pyogenes & Capture and kill bacteria & [7] \\
\hline Streptococcus pneumoniae & Capture and prevent spreading of bacteria & {$[37]$} \\
\hline $\begin{array}{l}\text { Salmonella enterica serovar } \\
\text { Typhimurium }\end{array}$ & Capture and kill bacteria & {$[3]$} \\
\hline Shigella flexneri & Capture and kill bacteria & {$[3]$} \\
\hline Escherichia coli & Capture and kill bacteria & [9] \\
\hline Candida albicans & Capture and kill hyphae or yeast & {$[10]$} \\
\hline Mycobacterium tuberculosis & Capture bacteria & {$[8]$} \\
\hline Mycobacterium canettii & Capture bacteria & {$[8]$} \\
\hline Listeria monocytogenes & Capture and kill bacteria & {$[8]$} \\
\hline Haemophilus influenzae & Biofilm formation and persistence & {$[36]$} \\
\hline Photorhabdus luminescens & Capture and kill bacteria & {$[53]$} \\
\hline Plasmodium falciparum & Unclear & {$[35]$} \\
\hline Intestinal spirochetosis & Unclear & {$[32]$} \\
\hline Leishmania amazonensis & Capture and kill parasite & {$[11]$} \\
\hline Bacterial sepsis & Upon platelet activation, potential endothelial injury & {$[6]$} \\
\hline \multicolumn{3}{|l|}{ Noninfectious disease } \\
\hline Appendicitis & Unclear & {$[3]$} \\
\hline Human preeclampsia & $\begin{array}{l}\text { Entrap and control release of proinflammatory placenta-derived syncytiotrophoblast } \\
\text { microparticles (STBM) }\end{array}$ & {$[44]$} \\
\hline Infertility of horses & Entrapment of sperm cells & {$[54]$} \\
\hline Autoimmune reactions & Unclear & {$[3,16]$} \\
\hline
\end{tabular}

Yost et al. recently demonstrated that neutrophils from term and preterm infants fail to form NETs when activated by inflammatory agonists that readily stimulate NET formation in adult neutrophils (e.g., LPS, PMA); consequently, a defect in the ability of the newborn neutrophils to carry out extracellular bacterial killing is appreciated [39]. Neutrophils and eosinophils from individuals with chronic granulomatous disease, an hereditary dysfunction of NADPH oxidase function and respiratory burst, are unable to form neutrophil or eosinophil extracellular traps [4, 32], an observation that might further explain the marked susceptibility of these patients to recurrent lifethreatening bacterial and fungal infections [40].

ETs are now recognized to be present in certain noninfectious diseases, as summarized in Table 2. NETs are also produced during sepsis after platelet-mediated neutrophil activation, and, though contributing to bacterial entrapment, the accumulation of NETs and their component proteases may promote vascular endothelial injury and ischemia [6]. Preeclampsia, a potentially lifethreatening pregnancy-related disorder, is characterized by neutrophil activation and a previously unexplainable high level of circulatory DNA of maternal origin [41-43]. In this scenario, NETs were able to entrap proinflammatory syncytiotrophoblast microparticles and thereby pos- sibly control the immune response by keeping inflammatory mediators from diffusing to adjacent healthy tissue [44]. Such a function for MCETs, i.e., to minimize collateral tissue damage by sequestering harmful compounds of MC granules such as proteolytic enzymes or histamines at the site of infection, has also been postulated [21].

It is interesting to speculate that dysregulated leakage of nucleic acids from neutrophils or MC or perhaps the failure of the host to efficiently clear ETs after their induction may have detrimental consequences leading to autoimmune phenomenon as seen in lupus erythematosus, where antibodies directed against nucleic acids and histones are a pathognomonic feature [3]. Recently, Neeli et al. [16] showed that deiminated histones, a covalently modified form of a prominent nuclear autoantigen, are released to the extracellular space as part of formation of NETs. The authors hypothesized that the possible association of a modified autoantigen with microbial components could, in predisposed individuals, increase the risk of autoimmunity [16]. In P. falciparum malaria, circulating neutrophilderived ETs bearing adherent parasites and erythrocytes are seen in concert with antinuclear immunoglobulin G. However, since a genetic model to eliminate expression of NETs or MCETs has not been realized, verification of the 
full contribution(s) of ETs to infectious, noninfectious, or autoimmune diseases remains challenging.

\section{Mechanisms of microbes to avoid entrapment or killing by ETs}

Perhaps the best evidence for a critical role of ETs in innate host defense has come from recent experimentation manipulating the microbial side of the host-pathogen equation. These studies have shown that certain leading bacterial pathogens have evolved mechanisms to avoid ETbased immune clearance, either through ET degradation, resistance to the intrinsic antimicrobial effectors with ETs, or the suppression of ET production (summarized in Table 4).

Shortly after the discovery of NETs, several independent groups demonstrated the ability of pathogenic bacteria to avoid entrapment and killing by NETs by production of DNA-degrading nucleases. Targeted elimination of DNase production in $S$. pyogenes, and in particular the potent bacteriophage-encoded DNase Sda1, rendered the pathogen more susceptible to neutrophil extracellular killing [7, 45]; correspondingly, heterologous expression of Sda1 in other bacterial strains conferred an ability to degrade NETs and resist neutrophil killing [7]. DNase-deficient GAS were attenuated for virulence in a murine necrotizing fasciitis model [7, 45], and pharmacological inhibition of DNase activity with G-actin provided a therapeutic benefit against GAS proliferation and tissue damage [7]. Acquisition of the bacteriophage encoding Sda1, and its upregulation during the genetic and phenotypic switch to the invasive phenotype [46], may help explain the global dissemination of a hypervirulent clone of M1 serotype $S$. pyogenes associated with severe human infections including necrotizing fasciitis [47]. Similar mutagenesis studies elegantly demonstrated that production of the DNase EndA by $S$. pneumoniae could degrade NETs, promote bacterial resistance to neutrophil killing, and contribute to virulence in a murine model of pneumococcal pneumonia [37].

$S$. pneumoniae expression of polysaccharide capsule, a classical virulence factor of the pathogen, significantly reduced the trapping of the bacterium within NETs, providing another potential mechanistic contribution of capsule to disease progression [48]. Cationic antimicrobial peptides such as cathelicidin are important effectors of bacterial killing within NETs. S. pneumoniae mutants lacking positively charged D-alanyl residues of their surface lipoteichoic acid (LTA) were more susceptible to killing by NET components, suggesting that these gene-encoded surface modifications are important for survival, especially in settings of low encapsulation [48]. D-alanylation of LTA by the dlt operon is known to contribute to resistance of $S$. pyogenes [49] and S. aureus [50] to cathelicidin antimicrobial peptides, which in turn are localized within NETs. Recently, it was shown that the surface-expressed M1 protein of S. pyogenes is able to bind cathelicidin LL-37 and prevent its bactericidal activity and, as a result, promote GAS survival within NETs and MCETs [12]. Nontypeable H. influenzae, a major etiologic agent of middle ear infections, expresses key lipooligosaccharide moieties that promote biofilm formation and allow the organism to survive within NETs in the middle ear cavity [36].

The inhibition of NET production provides a proximal means for pathogen avoidance of neutrophil extracellular killing. The chemokine IL-8, released by epithelial cells at the focus of infection and by recruited neutrophils themselves in amplifying the immune response, is a potent inducer of NET formation [4, 44]. S. pyogenes expresses a peptidase, SpyCEP, which cleaves and inactivates IL-8. Expression of SpyCEP was shown to reduce the level GASstimulated NET production and thus help the pathogen evade neutrophil extracellular killing [51]. Streptococcus agalactiae, a major cause of invasive infections in human newborns, expresses an exopolysaccharide capsule containing terminal sialic acid residues mimicking a common

Table 4 Mechanisms of microbes to avoid entrapment/killing in extracellular traps

\begin{tabular}{|c|c|c|}
\hline Microbe & Evasion strategy & References \\
\hline Streptococcus pyogenes & NET degradation by DNase Sda1/2 & {$[7,45]$} \\
\hline Streptococcus pyogenes & Reduction of NET production by IL-8 protease SpyCEP & {$[51]$} \\
\hline Streptococcus pyogenes & Resistance against LL-37-mediated killing within NETs/MCETs by surface M1 protein & {$[12]$} \\
\hline $\begin{array}{c}\text { Streptococcus } \\
\text { pneumoniae }\end{array}$ & NET-degradation by DNase EndA & {$[37]$} \\
\hline $\begin{array}{l}\text { Streptococcus } \\
\text { pneumoniae }\end{array}$ & $\begin{array}{c}\text { Preventing entrapment within NETs by capsule (serotype 1, 2, 4, } 9 \text { V) and D-alanylated lipoteichoic } \\
\text { acids (LTA) }\end{array}$ & [48] \\
\hline $\begin{array}{l}\text { Haemophilus } \\
\text { influenzae }\end{array}$ & Resistance against NET-killing by surface lipooligosaccharides & {$[36]$} \\
\hline $\begin{array}{l}\text { Streptococcus } \\
\text { agalactiae }\end{array}$ & Suppression of NETs by sialic acid engagement of Siglec receptors and consequent inhibitory signaling & {$[52]$} \\
\hline
\end{tabular}


glycoepitope on human cell surfaces. It was recently shown that $S$. agalactiae can engage Siglec receptors on human neutrophils via these sialic acid moieties, leading to negative cell signaling, suppression of the oxidative burst, and diminished NET production, thereby promoting resistance to neutrophil killing [52].

\section{Summary}

The process of microbial phagocytosis by white blood cells was originally described by the Russian microbiologist Ilya Metchnikov, a discovery for which he was awarded the Nobel Prize in Medicine or Physiology just over a century ago. The recent discoveries summarized herein of DNAbased ETs dramatically expand the antimicrobial repertoire of these highly specialized leukocytes and thus extend the playing field on which the battle against pathogens is fought from the intracellular to the extracellular compartment. The tenacious constituency of pus generated at primary foci of infection following neutrophil infiltration can now be viewed as a more physiologic and purposeful phenomenon - an immunological quicksand, so to speak, that serves to prevent spread and aid in sterilization by physically trapping microorganisms and directly exposing them to antimicrobial histones, peptides, and proteases. Leading human pathogens, it would seem, demonstrate mechanisms to avoid or escape ET that may be as pivotal to their virulence potential as resistance to phagocytosis; many more such ET survival capacities are certain to be discovered. And as for many other aspects of our immune defense, too much of a good thing can prove detrimental, and potential contributions of NETs to inflammatory and autoimmune diseases merit further exploration.

Acknowledgement M.v.K.-B. was supported through a fellowship from the Deutsche Akademie der Naturforscher Leopoldina (BMBFLPD 9901/8-187) and V.N. by NIH grant AI077780.

Open Access This article is distributed under the terms of the Creative Commons Attribution Noncommercial License which permits any noncommercial use, distribution, and reproduction in any medium, provided the original author(s) and source are credited.

\section{References}

1. Nathan C (2006) Neutrophils and immunity: challenges and opportunities. Nat Rev Immunol 6:173-182

2. Serbina NV, Jia T, Hohl TM, Pamer EG (2008) Monocytemediated defense against microbial pathogens. Annu Rev Immunol 26:421-452

3. Brinkmann V, Reichard U, Goosmann C, Fauler B, Uhlemann Y, Weiss DS, Weinrauch Y, Zychlinsky A (2004) Neutrophil extracellular traps kill bacteria. Science 303:1532-1535
4. Fuchs TA, Abed U, Goosmann C, Hurwitz R, Schulze I, Wahn V, Weinrauch Y, Brinkmann V, Zychlinsky A (2007) Novel cell death program leads to neutrophil extracellular traps. J Cell Biol 176:231-241

5. Martinelli S, Urosevic M, Daryadel A, Oberholzer PA, Baumann C, Fey MF, Dummer R, Simon HU, Yousefi S (2004) Induction of genes mediating interferon-dependent extracellular trap formation during neutrophil differentiation. J Biol Chem 279:44123-44132

6. Clark SR, Ma AC, Tavener SA, McDonald B, Goodarzi Z, Kelly MM, Patel KD, Chakrabarti S, McAvoy E, Sinclair GD, Keys EM, Allen-Vercoe E, Devinney R, Doig CJ, Green FH, Kubes P (2007) Platelet TLR4 activates neutrophil extracellular traps to ensnare bacteria in septic blood. Nat Med 13:463-469

7. Buchanan JT, Simpson AJ, Aziz RK, Liu GY, Kristian SA, Kotb M, Feramisco J, Nizet V (2006) DNase expression allows the pathogen group A Streptococcus to escape killing in neutrophil extracellular traps. Curr Biol 16:396-400

8. Ramos-Kichik V, Mondragon-Flores R, Mondragon-Castelan M, Gonzalez-Pozos S, Muniz-Hernandez S, Rojas-Espinosa O, Chacon-Salinas R, Estrada-Parra S, Estrada-Garcia I (2008) Neutrophil extracellular traps are induced by Mycobacterium tuberculosis. Tuberculosis (Edinb) 89:29-37

9. Grinberg N, Elazar S, Rosenshine I, Shpigel NY (2008) Betahydroxybutyrate abrogates formation of bovine neutrophil extracellular traps and bactericidal activity against mammary pathogenic Escherichia coli. Infect Immun 76:2802-2807

10. Urban CF, Reichard U, Brinkmann V, Zychlinsky A (2006) Neutrophil extracellular traps capture and kill Candida albicans yeast and hyphal forms. Cell Microbiol 8:668-676

11. Guimaraes-Costa AB, Nascimento MT, Froment GS, Soares RP, Morgado FN, Conceicao-Silva F, Saraiva EM (2009) Leishmania amazonensis promastigotes induce and are killed by neutrophil extracellular traps. Proc Natl Acad Sci U S A 106:6748-6753

12. Lauth X, von Köckritz-Blickwede M, McNamara CW, Myskowski S, Zinkernagel AS, Beall B, Ghosh P, Gallo RL, Nizet V (2009) M1 protein allows group A streptococcal survival in phagocyte extracellular traps through cathelicidin inhibition. J Innate Immun $1: 202-214$

13. Oehmcke S, Mörgelin M, Herwald H (2009) Activation of the human contact system on neutrophil extracellular traps. J Innate Immun 1:225-230

14. Pahlman LI, Morgelin M, Eckert J, Johansson L, Russell W, Riesbeck K, Soehnlein O, Lindbom L, Norrby-Teglund A, Schumann RR, Bjorck L, Herwald H (2006) Streptococcal M protein: a multipotent and powerful inducer of inflammation. $\mathrm{J}$ Immunol 177:1221-1228

15. Steinberg BE, Grinstein S (2007) Unconventional roles of the NADPH oxidase: signaling, ion homeostasis, and cell death. Sci STKE 2007:pe11

16. Neeli I, Khan SN, Radic M (2008) Histone deimination as a response to inflammatory stimuli in neutrophils. J Immunol 180:1895-1902

17. Wang Y, Li M, Stadler S, Correll S, Li P, Wang D, Hayama R, Leonelli L, Han H, Grigoryev SA, Allis CD, Coonrod SA (2009) Histone hypercitrullination mediates chromatin decondensation and neutrophil extracellular trap formation. J Cell Biol 184:205213

18. Frick IM, Bjorck L, Herwald H (2007) The dual role of the contact system in bacterial infectious disease. Thromb Haemost 98:497-502

19. Frick IM, Akesson P, Herwald H, Morgelin M, Malmsten M, Nagler DK, Bjorck L (2006) The contact system-a novel branch of innate immunity generating antibacterial peptides. EMBO J 25:5569-5578 
20. Jaillon S, Peri G, Delneste Y, Fremaux I, Doni A, Moalli F, Garlanda C, Romani L, Gascan H, Bellocchio S, Bozza S, Cassatella MA, Jeannin P, Mantovani A (2007) The humoral pattern recognition receptor PTX3 is stored in neutrophil granules and localizes in extracellular traps. J Exp Med 204:793-804

21. von Köckritz-Blickwede M, Goldmann O, Thulin P, Heinemann K, Norrby-Teglund A, Rohde M, Medina E (2008) Phagocytosisindependent antimicrobial activity of mast cells by means of extracellular trap formation. Blood 111:3070-3080

22. Puxeddu I, Piliponsky AM, Bachelet I, Levi-Schaffer F (2003) Mast cells in allergy and beyond. Int J Biochem Cell Biol 35:1601-1607

23. Bischoff SC, Kramer S (2007) Human mast cells, bacteria, and intestinal immunity. Immunol Rev 217:329-337

24. Galli SJ, Wershil BK (1996) The two faces of the mast cell. Nature 381:21-22

25. Feger F, Varadaradjalou S, Gao Z, Abraham SN, Arock M (2002) The role of mast cells in host defense and their subversion by bacterial pathogens. Trends Immunol 23:151-158.

26. Di Nardo A, Vitiello A, Gallo RL (2003) Cutting edge: mast cell antimicrobial activity is mediated by expression of cathelicidin antimicrobial peptide. J Immunol 170:2274-2278

27. Wei OL, Hilliard A, Kalman D, Sherman M (2005) Mast cells limit systemic bacterial dissemination but not colitis in response to Citrobacter rodentium. Infect Immun 73:1978-1985

28. Wartha F, Henriques-Normark B (2008) ETosis: a novel cell death pathway. Sci Signal 1:pe25

29. Rothenberg ME, Hogan SP (2006) The eosinophil. Annu Rev Immunol 24:147-174

30. DeBrosse CW, Rothenberg ME (2008) Allergy and eosinophilassociated gastrointestinal disorders (EGID). Curr Opin Immunol 20:703-708

31. Wedemeyer J, Vosskuhl K (2008) Role of gastrointestinal eosinophils in inflammatory bowel disease and intestinal tumours. Best Pract Res Clin Gastroenterol 22:537-549

32. Yousefi S, Gold JA, Andina N, Lee JJ, Kelly AM, Kozlowski E, Schmid I, Straumann A, Reichenbach J, Gleich GJ, Simon HU (2008) Catapult-like release of mitochondrial DNA by eosinophils contributes to antibacterial defense. Nat Med 14:949-953

33. Nizet V, Rothenberg ME (2008) Mitochondrial missile defense. Nat Med 14:910-912

34. Brinkmann V, Zychlinsky A (2007) Beneficial suicide: why neutrophils die to make NETs. Nat Rev Microbiol 5:577-582

35. Baker VS, Imade GE, Molta NB, Tawde P, Pam SD, Obadofin MO, Sagay SA, Egah DZ, Iya D, Afolabi BB, Baker M, Ford K, Ford R, Roux KH, Keller TC 3rd (2008) Cytokine-associated neutrophil extracellular traps and antinuclear antibodies in Plasmodium falciparum infected children under six years of age. Malar J 7:41

36. Hong W, Juneau RA, Pang B, Swords WE (2009) Survival of bacterial biofilms within neutrophil extracellular traps promotes nontypeable Haemophilus influenzae persistence in the chinchilla model for otitis media. J Innate Immun 1:215-224

37. Beiter K, Wartha F, Albiger B, Normark S, Zychlinsky A, Henriques-Normark B (2006) An endonuclease allows Streptococcus pneumoniae to escape from neutrophil extracellular traps. Curr Biol 16:401-407

38. Lippolis JD, Reinhardt TA, Goff JP, Horst RL (2006) Neutrophil extracellular trap formation by bovine neutrophils is not inhibited by milk. Vet Immunol Immunopathol 113:248-255

39. Yost CC, Cody MJ, Harris ES, Thornton NL, McInturff AM, Martinez ML, Chandler NB, Rodesch CK, Albertine KH, Petti
CA, Weyrich AS, Zimmerman GA (2009) Impaired neutrophil extracellular trap (NET) formation: a novel innate immune deficiency of human neonates. Blood (in press)

40. Heyworth PG, Cross AR, Curnutte JT (2003) Chronic granulomatous disease. Curr Opin Immunol 15:578-584

41. Zhong XY, Holzgreve W, Hahn S (2001) Circulatory fetal and maternal DNA in pregnancies at risk and those affected by preeclampsia. Ann N Y Acad Sci 945:138-140

42. Redman CW, Sargent IL (2005) Latest advances in understanding preeclampsia. Science 308:1592-1594

43. Gupta AK, Hasler P, Holzgreve W, Hahn S (2007) Neutrophil NETs: a novel contributor to preeclampsia-associated placental hypoxia? Semin Immunopathol 29:163-167

44. Gupta AK, Hasler P, Holzgreve W, Gebhardt S, Hahn S (2005) Induction of neutrophil extracellular DNA lattices by placental microparticles and IL-8 and their presence in preeclampsia. Hum Immunol 66:1146-1154

45. Sumby P, Barbian KD, Gardner DJ, Whitney AR, Welty DM, Long RD, Bailey JR, Parnell MJ, Hoe NP, Adams GG, Deleo FR, Musser JM (2005) Extracellular deoxyribonuclease made by group A Streptococcus assists pathogenesis by enhancing evasion of the innate immune response. Proc Natl Acad Sci U S A 102:1679-1684

46. Sumby P, Whitney AR, Graviss EA, DeLeo FR, Musser JM (2006) Genome-wide analysis of group A streptococci reveals a mutation that modulates global phenotype and disease specificity. PLoS Pathog 2:e5

47. Walker MJ, Hollands A, Sanderson-Smith ML, Cole JN, Kirk JK, Henningham A, McArthur JD, Dinkla K, Aziz RK, Kansal RG, Simpson AJ, Buchanan JT, Chhatwal GS, Kotb M, Nizet V (2007) DNase Sda1 provides selection pressure for a switch to invasive group A streptococcal infection. Nat Med 13:981-985

48. Wartha F, Beiter K, Albiger B, Fernebro J, Zychlinsky A, Normark S, Henriques-Normark B (2007) Capsule and Dalanylated lipoteichoic acids protect Streptococcus pneumoniae against neutrophil extracellular traps. Cell Microbiol 9:1162-1171

49. Kristian SA, Datta V, Weidenmaier C, Kansal R, Fedtke I, Peschel A, Gallo RL, Nizet V (2005) D-alanylation of teichoic acids promotes group a streptococcus antimicrobial peptide resistance, neutrophil survival, and epithelial cell invasion. J Bacteriol 187:6719-6725

50. Kraus D, Herbert S, Kristian SA, Khosravi A, Nizet V, Gotz F, Peschel A (2008) The GraRS regulatory system controls Staphylococcus aureus susceptibility to antimicrobial host defenses. BMC Microbiol 8:85

51. Zinkernagel AS, Timmer AM, Pence MA, Locke JB, Buchanan JT, Turner CE, Mishalian I, Sriskandan S, Hanski E, Nizet V (2008) The IL-8 protease SpyCEP/ScpC of group A Streptococcus promotes resistance to neutrophil killing. Cell Host Microbe 4:170-178

52. Carlin AF, Uchiyama S, Chang YC, Lewis AL, Nizet V, Varki A (2009) Molecular mimicry of host sialylated glycans allows a bacterial pathogen to engage neutrophil Siglec-9 and dampen the innate immune response. Blood 113:3333-3336

53. Altincicek B, Stotzel S, Wygrecka M, Preissner KT, Vilcinskas A (2008) Host-derived extracellular nucleic acids enhance innate immune responses, induce coagulation, and prolong survival upon infection in insects. J Immunol 181:2705-2712

54. Alghamdi AS, Foster DN (2005) Seminal DNase frees spermatozoa entangled in neutrophil extracellular traps. Biol Reprod $73: 1174-1181$ 